\title{
Implicaciones sociales del gasto de intereses sobre la deuda pública en Costa Rica: una aproximación
}

Rodrigo Matarrita Venegas*

* Escuela de Economía, Universidad de Costa Rica, Apartado 1424-3000 Heredia, Costa Rica. E-mail: rmatarrita@bolsacr.com.

Recibido: septiembre de 2006 / Aceptado: octubre de 2006

LA FORMA EN LA QUE EL GOBIERNO DE LA REPÚBLICA DE COSTA RICA ha ido modificando su deuda pública ha incidido en la definición de un importante peso en cuanto al pago de intereses, lo que ha afectado la acción de Estado en cuanto a la redistribución de la riqueza, favoreciendo la acumulación del capital financiero de los agentes con excedentes de recursos. El documento procura establecer el uso de un par de indicadores como variables aproximadas de este fenómeno.

Palabras clave: Deuda pública-Costa Rica / fondos de amortización / Costa Ricapolítica económica

\section{Antecedentes}

El Gobierno de la República de Costa Rica mantenía hasta finales de la década de los años setentas una estructura de financiamiento bonificada ciertamente programada, en la que, de la respectiva Ley de Presupuesto de la República, se desprendían los flujos correspondientes para los pagos de amortización y servicio de tal deuda; más aún, tal era la predictibilidad de los flujos derivados del endeudamiento bonificado, que los documentos fiscales contenían una cláusula de sorteo, en donde el inversionista tenedor del título favorecido era merecedor de una recuperación anticipada del principal y del total de intereses.

La crisis vivida hacia finales de la década de los años setentas, provocada, por un lado, por circunstancias externas adversas (caída en los precios del café y alza en los precios de los hidrocarburos) y, por otro, a esquemas rígidos en cuanto al manejo de las tasas de interés y del tipo de cambio (ambos era fijados por el Banco Central de Costa Rica), llevó a un severo ajuste de los precios internos, que se convirtieron en la válvula de escape y de acomodo ante los desequilibrios macroeconómicos.

El fenómeno inflacionario provocó la aparición de rendimientos reales negativos sobre 
las inversiones financieras, a las sazones constituidas casi estrictamente por los bonos del gobierno y los certificados bancarios. En este escenario, los instrumentos de inversión gubernamentales, emitidos por medio de la Ley de Presupuesto, en condiciones estándares y de características totalmente rígidas (en cuanto a plazos, tasas de interés y periodicidades), perdieron rápidamente atractivo para los inversionistas.

Para hacerlos atractivos se implementaron distintas estrategias de colocación, desde la venta compulsiva entre entidades públicas superavitarias, hasta el resello de tasas y refundición de emisión en nuevas emisiones financieramente más atractivas para los inversionistas. No obstante, con el transcurso del tiempo las posibilidades fueron limitándose cada vez más.

Con este panorama, la colocación de la deuda bonificada se dificultó en extremo, dada su condición de largo plazo, bajas tasas de interés y bajos montos (Matarrita y Ledezma, 2004). La urgencia de recursos para financiar el déficit fiscal, por un lado, y por otro, las limitaciones crediticias impuestas por la declaratoria de mora internacional y los convenios de stand by con el Fondo Monetario Internacional, estimularon la búsqueda de nuevas fuentes y formas de financiamiento por parte del Gobierno Central.

Es así como, a finales del año 1982, casi como un preámbulo al establecimiento de los convenios de estabilización con el FMI, el Gobierno aprovecha la oportunidad que le brindara el mercado de valores (que había empezado a funcionar en forma oficial a partir del año 1976) e incursiona en el desarrollo y creación de nuevos instrumentos, a los que se dio el nombre familiar de "Bonos del Decreto", pues se emitieron no mediante una ley, sino mediante un decreto ejecutivo, poniendo en garantía los anteriores Bonos de Deuda Interna emitidos y no colocados en el mercado de valores.

El experimento financiero resultó exitoso en términos del objetivo básico de recaudación, y es así que, mediante Decreto 15966-H del 14 de enero de 1985, se reglamenta la operación de los “Títulos de Propiedad sobre Bonos Deuda Interna” (TP/BDI) los cuales tienen características más versátiles y acordes con las imperantes en el mercado.

Estos títulos estarían respaldados por Bonos Deuda Interna, los que tienen características predefinidas y autorizados mediante la Ley de Presupuesto de la República. Los TP/BDI por ser más flexibles, adquirieron gran atractivo y permitieron, por ejemplo, la reinversión de los intereses y la definición de una estructura temporal de tasas de interés (ETTI).

La existencia de instrumentos heterogéneos y algunos de manejo complejo, ha llevado al Ministerio de Hacienda durante los últimos años, a realizar esfuerzos importantes para modificar su oferta de títulos valores, con el propósito de reducir el costo del financiamiento del déficit y de brindar una mayor liquidez y profundidad al mercado financiero costarricense.

Sin embargo, los distintos "experimentos de ingeniería financiera" derivaron en la creación de una deuda muy cara, debido a que ésta tomó la forma de una deuda de corto plazo y con intereses fluctuantes. Ello obliga a la Tesorería a una constante colocación de instrumentos para la cancelación de los saldos e intereses, dificultándose la programación y presupuesto de los gastos respectivos por conceptos de amortización e intereses. 
En estas condiciones, el manejo de la deuda se ha convertido prácticamente en un crédito revolutivo y capitalizable, puesto que implica la emisión de deuda para pagar intereses, convirtiendo así la deuda interna en una verdadera "bola de nieve creciente", dado que la nueva deuda así creada está conformada por un conjunto de emisiones muy poco estandarizadas (lo que significa que no son emisiones en serie ${ }^{1}$ ) generando además, con ello, mayores trámites burocráticos y los consiguientes gastos de administración.

En resumen, dado que como el propósito era básicamente captar suficientes recursos, sin que mediara una adecuada restricción presupuestaria (el objetivo era obtener los recursos sin que hubiese restricciones en cuanto al costo), los instrumentos se adecuaban a las condiciones que imponía la demanda de activos financieros. Esto cambió radicalmente el perfil de la deuda, cuyas características históricas respondían a un tipo de deuda dirigida al financiamiento de proyectos específicos, de largo plazo, de fácil previsión en cuanto a su servicio y de fácil manejo administrativo y financiero, con características altamente homogéneas en los documentos.

El nuevo tipo de endeudamiento cambió hacia la atención de las necesidades de financiamiento para los gastos corrientes y el servicio de la propia deuda (Matarrita, 1993b), con características de una deuda de corto plazo, de elevada rotación y difícil manejo, dada la disparidad generada por las diferencias de tasas, montos y plazos.

La flexibilización en las condiciones de emisión que generó la colocación de los Títulos de Propiedad Deuda Interna alivió, en principio, la afluencia en cuanto a la provisión de recursos para Gobierno Central. No obstante, conforme el problema fiscal comenzó a cobrar mayores dimensiones, con una estructura de los vencimientos sobrecargada en el corto plazo, los problemas de control y presupuesto del flujo de caja se complicaron enormemente.

\section{Efectos en el manejo del servicio de la deuda}

El cambio en la conformación de la deuda pública, trajo consigo implicaciones de orden macroeconómico sobre la distribución de los recursos disponibles de la economía, que han encontrado en la inversión en títulos del Gobierno un nicho cómodo y atractivo, lo que ha encarecido los costos de financiamiento.

La carga que representa el pago de los intereses sobre el monto correspondiente a los ingresos corrientes totales percibidos por el Gobierno, ha mostrado un claro comportamiento ascendente. Esto evidencia la presencia de un fuerte elemento de capitalización del endeudamiento, debido a que los ingresos son cada vez menos suficientes para cubrir la carga que representan los intereses. 


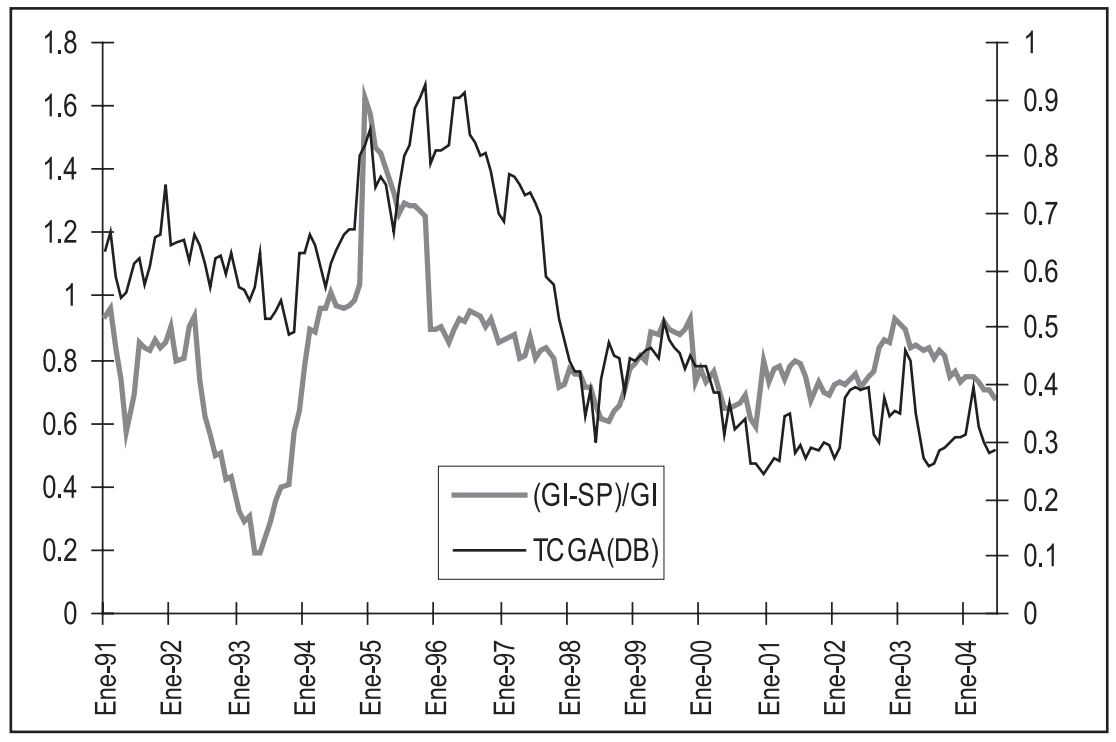

Ilustración 1. Costa Rica: Exceso de los Gastos de Intereses sobre el Superávit Primario y Tasa de Crecimiento Geométrico Anual de la Deuda Bonificada del Gobierno Central Enero 1991 - Junio 2004

Fuente: Elaboración propia, partiendo de cifras recopiladas por CEFSA.

La ilustración precedente muestra, como porcentaje, el exceso de los Gastos de Intereses por encima del monto de Superávit Primario del Gobierno ${ }^{2}$, lo que puede interpretarse como la necesidad de financiamiento para cubrir el Gasto de Intereses. Como se aprecia, por más de quince años el Gobierno ha tenido que financiar el Gasto de Intereses por medio de endeudamiento, por cifras que representan cerca del 80\% de los intereses pagados.

Este exceso del Gasto de Intereses sobre el Superávit Primario del Gobierno se transforma, como se observa, en uno de los elementos propiciadores del crecimiento del endeudamiento bonificado, medido en la ilustración como la tasa de crecimiento geométrico anualizado (TCGA) del saldo de la deuda bonificada ${ }^{3}$.

De esta manera, la conformación de la deuda bonificada ha ido adquiriendo la forma financiera de un "crédito revolutivo y capitalizable" que crece en forma exponencial; siendo la carga del Gasto de Intereses no cubierto con el Superávit Primario el vehículo de expansión de tal deuda.

El anterior análisis pone de manifiesto que el problema radica en que la deuda pública se ha utilizado para cubrir gastos de consumo (salarios, pensiones y aún intereses) y no para invertir en bienes y servicios de carácter social. Por otro lado, el servicio de la deuda representa poco más de un tercio de los gastos totales del Gobierno Central, lo que deja muy poco para financiar programas sociales como educación y salud, así como para el desarrollo de la infraestructura que el país necesita para su desarrollo. 
Cuadro 1. Costa Rica: Gastos de Intereses a Ingresos Corrientes; Gastos de Intereses a Gastos Totales y Financiamiento con Bonos a Déficit Financiero

Cifras en porcentajes, 1991- 2004

\begin{tabular}{|c|c|c|c|}
\hline Año & $\begin{array}{c}\text { Gastos de Intereses a } \\
\text { Ingresos Corrientes }\end{array}$ & $\begin{array}{c}\text { Gastos de Intereses a } \\
\text { Gastos Totales }\end{array}$ & $\begin{array}{c}\text { Financiamiento con } \\
\text { Bonos a Deficit } \\
\text { Financiero }\end{array}$ \\
\hline 1991 & 25,64 & 22,04 & 171,02 \\
1992 & 26,12 & 23,48 & 139,27 \\
1993 & 22,74 & 19,86 & 244,30 \\
1994 & 27,41 & 18,95 & 105,39 \\
1995 & 37,25 & 27,94 & 142,26 \\
1996 & 37,07 & 28,17 & 134,75 \\
1997 & 31,14 & 25,42 & 147,18 \\
1998 & 26,10 & 21,73 & 154,42 \\
1999 & 31,15 & 25,41 & 60,70 \\
2000 & 29,32 & 23,76 & 18,49 \\
2001 & 30,52 & 25,74 & 95,46 \\
2002 & 33,22 & 25,39 & 72,63 \\
\hline 2003 & 32,22 & 26,05 & 65,79 \\
\hline $2004^{*}$ & 32,30 & 26,49 & 93,03 \\
\hline
\end{tabular}

* A Junio del 2004

Fuente: elaboración propia, partiendo de cifras recopiladas por CEFSA.

Importante es hacer notar que el peso de de los gastos de intereses sobre la deuda ha venido creciendo independientemente de la forma en la que ésta se ha generado. Por ejemplo, hasta el año 1998, el financiamiento mediante la colocación de bonos en el mercado local representaba cifras por encima de lo necesario, lo que manifiesta un claro proceso de utilización de recursos domésticos para la amortización de la deuda externa ${ }^{4}$.

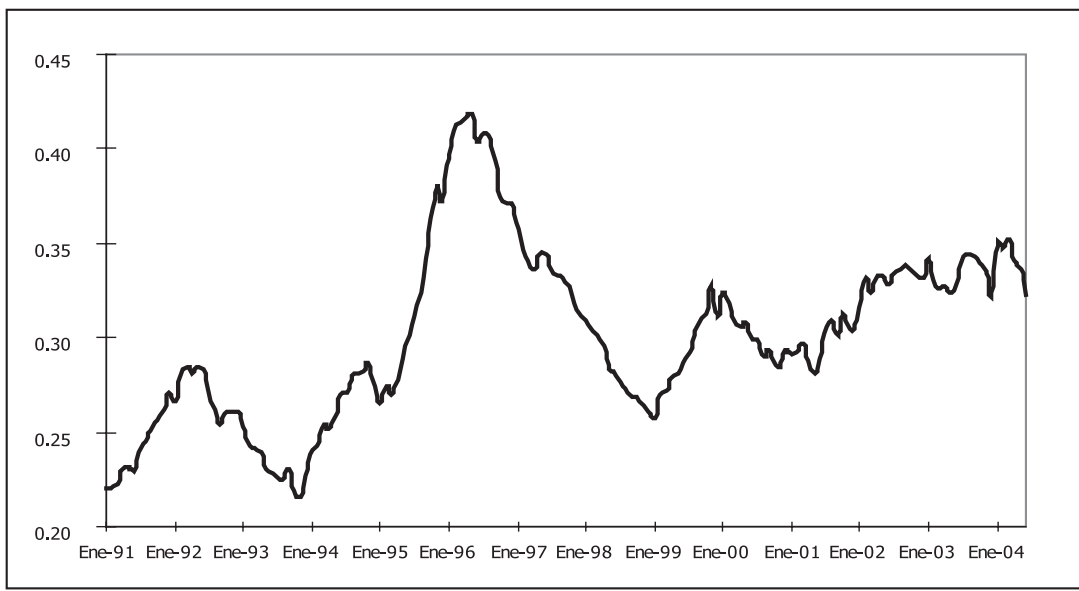

Ilustración 2. Costa Rica: Relación de Gastos de Intereses a Ingresos Corrientes Totales Enero 1991 - Junio 2004

Cifras sobre montos anualizados

Fuente: Elaboración propia, partiendo de cifras recopiladas por CEFSA 
Las subsecuentes colocaciones en el exterior de deuda bonificada han redundado en una reducción de la dependencia de los recursos domésticos, pero no así de la carga de los intereses, los cuales han mostrado una clara tendencia de ascenso a lo largo de los últimos quince años.

Lo anterior permite afirmar, no obstante, que la Deuda Pública no es en sí un problema, dado que bien administrada puede generar ingresos suficientes para pagar los intereses y la amortización del endeudamiento. Sin embargo, en Costa Rica el problema radica en la forma en que la deuda pública ha sido utilizada (Quintero y Romero, 2004).

Así, aún desde el estricto cumplimiento de la equivalencia ricardiana, el endeudamiento puede verse como una forma apropiada de financiar un proyecto, siempre que los réditos sean suficientes para generar la riqueza adicional para obtener los recursos fiscales (mediante impuestos), para cancelar los servicios de la deuda y la cancelación del saldo. El problema no es la forma en que se dé financiamiento per se, es el uso o aplicación que se le de a tal financiamiento.

Desde este punto de vista, cualquier proyecto o emprendimiento deberá ser factible si puede soportar el peso de una forma de financiamiento específica, si no, no se considera financieramente factible. El problema surge cuando parte del financiamiento proveniente del endeudamiento no es empleado para sostener un proyecto capaz de generar riqueza, aún en forma intertemporal, como podría ser la educación o la salud (que incrementan el acervo de capital humano), o cualquier obra de infraestructura pública; sino que se emplea en alguna actividad no reproductiva ni contemporánea, ni intertemporalmente, tal como el gasto o, peor aún, el pago de intereses, convirtiendo la deuda de un mecanismo de financiamiento, en uno de redistribución perversa de la riqueza al interior de la economía.

\section{Implicaciones en las finanzas públicas}

El comportamiento creciente de la carga del pago de intereses sobre los ingresos ha incidido definitivamente en la definición de las políticas de administración de la Hacienda Pública. De hecho, los problemas de financiamiento del déficit financiero han cedido importancia a los problemas "por encima de la línea", dado el peso que representan los intereses en la conformación del gasto público.

Salvando las excepciones de los años 1993 y 1994, en donde el pago de intereses representó menos del 20\% de los gastos totales del Gobierno, en el resto de los años considerados en el Cuadro 1, se observa que entre una de cada cinco y una de cada cuatro unidades monetarias destinadas al gasto gubernamental corresponden al pago de intereses, lo cual incide, definitivamente, en el manejo de las finanzas públicas. 


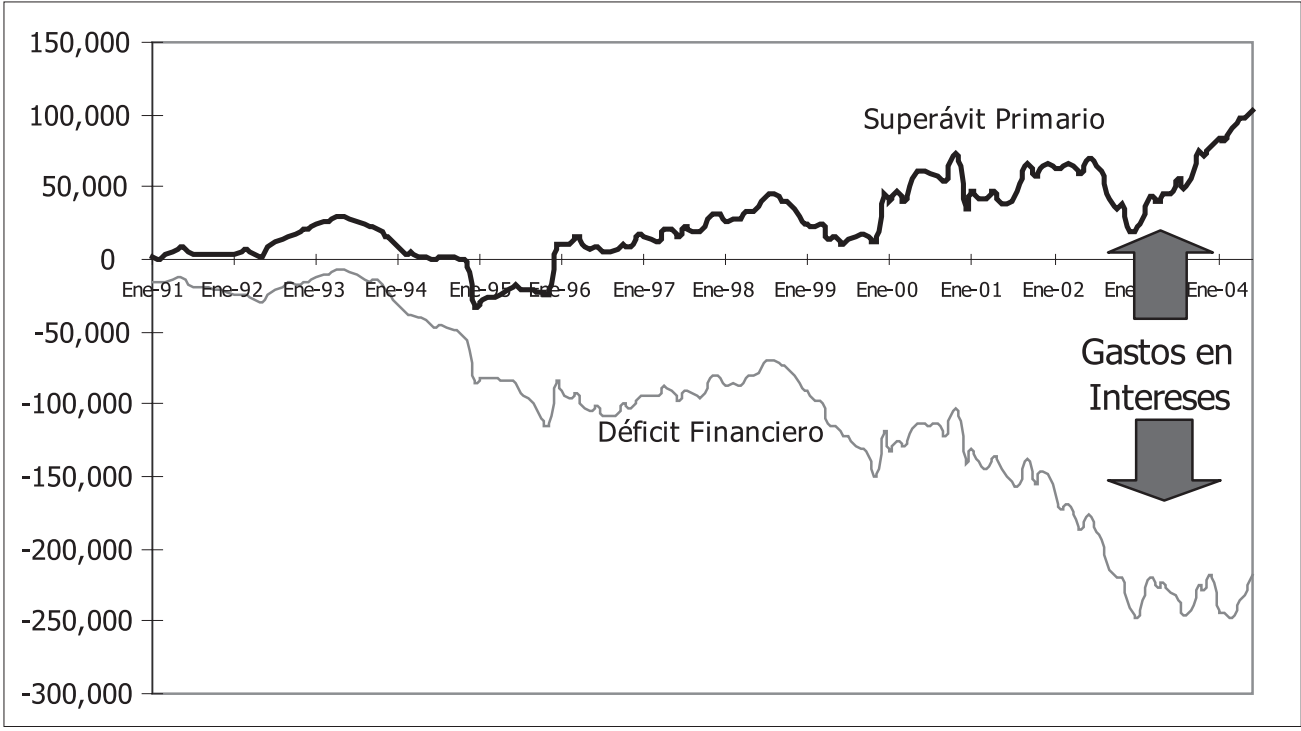

Ilustración 3. Costa Rica: Superávit (Déficit) Primario y Déficit Financiero

Enero 1991 - Junio 2004

Cifras anualizadas en millones de colones corrientes

Fuente: Elaboración propia, partiendo de cifras recopiladas por CEFSA

Justamente el grave peso que este elemento representa hace que una situación de "virtud financiera", representada por la existencia de reiterados superávit primarios, se trueque por una de déficit financiero. En otras palabras, el pago de intereses transforma una situación de relativa salud financiera, en donde la recaudación corresponde en forma suficiente a los gastos y la acción de Estado que corresponde al Gobierno en la redistribución de la riqueza y la prestación de servicios, en una en la que el ahorro gestado no es suficiente para satisfacer el servicio comprometido en la utilización de ingresos futuros.

El recurrente crecimiento del déficit financiero del Gobierno, como se puede apreciar en la ilustración anterior, sólo ha podido frenarse para los últimos años merced a un incremento en el superávit primario del Gobierno, no por algún comportamiento menguante en el rubro de los intereses, como se puede apreciar en el Cuadro 1.

Lo anterior lleva a considerar el importante esfuerzo que está llevando a cabo el Gobierno en la administración de las finanzas públicas, por incrementar la recaudación y por contener el gasto corriente (es decir, la implementación de una política ciertamente austera "por encima de la línea"). Sin embargo, ello apenas ha servido para frenar el impacto que sobre el déficit financiero tiene la vorágine del Gasto por Intereses.

Más grave puede considerarse la situación cuando se contempla que buena parte de la reducción en la ejecución de proyectos de infraestructura, programas de asistencia social y transferencias (es decir, la típica acción del Estado como redistribuidor de la riqueza y proveedor de servicios públicos), se ve apocada por la atención del problema de pago de los intereses. 


\section{Implicaciones sociales del gasto de intereses: Una aproximación}

La desatención de los programas sociales y el freno en la ejecución de las obras de infraestructura pública como medida para generar superávit primario, ha sido una política que ha tenido implicaciones de orden social importantes, las cuales deben haber incidido en la calidad de la prestación de servicios públicos (educación, seguridad ciudadana, infraestructura vial, etc.); así comola labor de redistribución de ingresos y riqueza (programas de asistencia social, política habitacional, salud pública, transferencias directas, etc.).

Ciertamente, el asumir el costo de oportunidad social implícito en la desatención de las necesidades básicas, en aras del servicio de la deuda, ha debido ser una decisión nada trivial ni fácil, que ha tocado ser tomada por las distintas administraciones de turno. Además, cediendo a la siguiente el asumir una espiral deficitaria en las labores económicas y sociales, propias de Estado, en pos de la atención del Gasto de Intereses, sin que ello haya representado algo menos que un paliativo en la explosión que significa el crecimiento del monto pagado en intereses, como proporción de los problemas que debe enfrentar el administrador de la Hacienda Pública.

Un par de indicadores pueden permitir apreciar este fenómeno con un poco más de claridad. El primero de ellos se establecerá como una métrica de la equidad en la distribución del gasto. Para ello se medirá la proporción que representa el Gasto de Intereses con respecto al gasto destinado por el Gobierno a las transferencias destinadas a las personas, entre los que se incluyen los pagos de pensiones, bonos familiares de vivienda, asistencia a programas como Asignaciones Familiares y Comedores Escolares (descontando los montos correspondientes a los Certificados de Abono Tributario, CAT, por considerarse transferencias al sector empresarial); esto como una medida proxy de la acción social del Estado, lo que puede expresarse mediante la siguiente fórmula:

$$
I I G=\frac{G I}{\operatorname{Tr} N}
$$

Donde IIG, es el Indicador de Inequidad del Gasto; GI es el Gasto en Intereses, $T r N$, son las Transferencias Netas (Transferencias menos CAT).

Los datos que arroje este indicador mostrarán un mejoramiento de la situación en cuanto a la atención de la acción del Estado, en tanto la proporción de los Gastos en Intereses disminuyan en comparación con los gastos en transferencias destinadas a las personas. Consecuentemente, conforme el indicador aumente, más destinará el Gobierno al servicio de la deuda y menos a su acción social.

El otro indicador propuesto es consecuencia del anterior. Procura hallar una métrica para determinar una aproximación a la redistribución de la riqueza que implica el Gasto en Intereses. El pago de intereses representa una retribución al uso del capital financiero, por lo cual es considerado como un ingreso por el uso de tal factor a sus dueños, como contribución al proceso productivo. El pago de este ingreso a los dueños del capital 
financiero representa, por tanto, una forma de redistribución de la riqueza al interior de una organización económica, que puede contrastarse con el gasto realizado por el Gobierno en el pago de transferencias a las personas, que representa la labor directa en la distribución del ingreso llevada a cabo por el Estado.

Ahora bien, siendo ambos rubros de gasto (los intereses y las transferencias) usos que determinan la estructura de distribución de los ingresos llevada a cabo por la intervención del Estado, resulta interesante apreciar cómo se sostienen ambos usos de los ingresos recaudados por el Gobierno. Para ello se emplearán las cifras de la recaudación del Impuesto sobre Renta, en que se identifica claramente una exacción de ingreso de algunos de los ciudadanos, para ser canalizados en forma de nuevos ingresos a otros ciudadanos gracias a la acción de imperio del Estado.

De esta manera, al contrastar cuánto de la recaudación por concepto de Impuesto sobre Renta es destinado al pago de transferencias a las personas, puede percibirse la acción redistributiva de parte del Estado. Valores altos de este indicador darán muestras de una mayor proporción de lo recaudado hacia la acción de redistribución del ingreso por parte del Gobierno; valores bajos de este indicador serán muestra de una mengua en este tipo de acciones para dar cabida a otro tipo de gastos (entre los cuales estarían los intereses, por ejemplo). Lo anterior puede expresarse de la siguiente forma:

$$
I R P=\frac{\operatorname{Tr} N}{I S R}
$$

Donde IRP, es el Indicador de Redistribución Perversa; TrN, son las Transferencias Netas y ISR, es el Impuesto sobre Renta. Los resultados de los cálculos realizados se exponen a continuación, en la Ilustración 4.

$\mathrm{Al}$ analizar este indicador, se aprecia que ha habido épocas, como la que se extiende desde principios de 1996 hasta finales del 2000, en donde este indicador muestra un claro deterioro de la situación, puesto que la atención prioritaria en cuanto al gasto por parte del Gobierno ha sido el servicio de la deuda, merced al detrimento registrado en la atención en su acción social de Estado. Por ejemplo, en marzo de 1996, este indicador reflejaba que por cada unidad monetaria destinada al gasto en transferencias, se destinaban 2,2 al servicio de la deuda.

Comparando el desempeño del indicador de inequidad del gasto, es hasta entrado el nuevo milenio que se muestra una mejora con respecto a la situación prevaleciente en enero del año 1991, llegándose a observar el valor más bajo de la serie considerada en diciembre del 2002 , cuando, por cada unidad monetaria destinada al gasto en transferencias, se destinaban al servicio de la deuda solamente 0,69 unidades monetarias.

No obstante, esta mejora parece ser no permanente, toda vez que se considere el repunte mostrado en la tendencia, llegando, hacia mediados del año 2004, a situaciones similares a la registrada en Enero de 1991. 


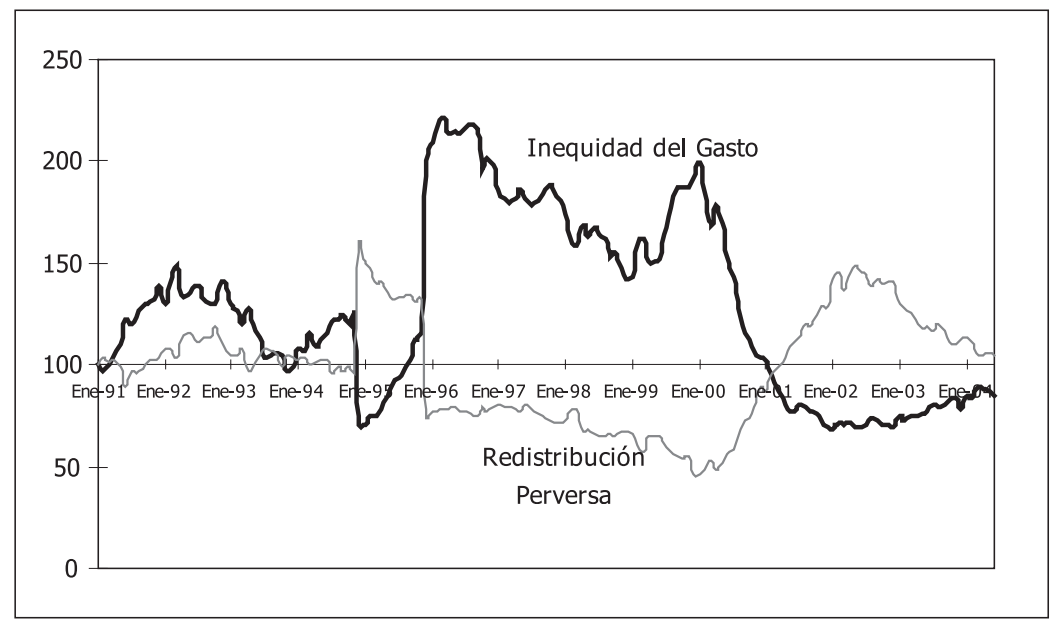

Ilustración 4. Costa Rica: Índices de los Indicadores de Inequidad del Gasto y Redistribución Perversa

Enero 1991 - Junio 2004

Cifras, en porcentajes. Base Enero $1991=100$

Fuente: Elaboración propia, partiendo de cifras recopiladas por CEFSA

El análisis no deja de llamar la atención cuando se introducen los datos correspondientes al indicador de redistribución de los ingresos recaudados por el Gobierno, percibiéndose la existencia de una "Redistribución Perversa", debido a que la exacción de ingresos que representa el Impuesto sobre Renta, no es canalizada al pago de transferencias a las personas, sino que una buena parte se canaliza al pago de intereses, los cuales, como se ha visto ya, demandan una cada vez mayor proporción de los ingresos corrientes del Gobierno.

Esto convierte al Gobierno en un redistribuidor del ingreso, que extrae recursos de los generadores de renta para canalizarla a los dueños del capital financiero. Y son ellos quienes gozan de recursos en forma excedente para destinarlos a la inversión financiera. El Gobierno asume aquí una versión "malvada" de Robin Hood, en donde son los generadores de riqueza (los que ganan rentas) quienes terminan acrecentando la de aquellos que ya la poseen, gracias a la intervención del Estado por medio del pago de intereses, convirtiéndose éste en el mecanismo de acumulación de capital.

De esta manera, la extracción de riqueza desde las fuentes generadoras de renta, hasta su transformación en acumulación del capital, se da por medio no de la plusvalía del trabajo, sino por medio del pago de intereses de la deuda pública del Gobierno; convirtiéndose éste en el mecanismo de acumulación sobre el capital, dentro del modelo de producción propuesto. De esta forma, la intervención del Estado, más allá de un redistribuidor de la riqueza intergeneracional, se ve aquí como el perfecto socio del acentuamiento del proceso desigual del acceso a los medios de producción y del proceso de acumulación del capital físico, humano y financiero. 
Más aún, podría derivarse de la aplicación de [1] y [2], lo siguiente: [1] x [2] = [3], de la siguiente manera:

$I I G \times I R P=\frac{G I}{T r N} \times \frac{T r N}{I S R}=\frac{G I}{I S R}=\tau$

Donde $\tau$ se puede interpretar como la “Tasa de Acumulación del Capital Financiero", la cual será el producto de la "Inequidad del Gasto" y de la "Redistribución Perversa”. Diferenciando [3] se tiene que

$$
d I I G+d I R P=d G I-d I S R \quad[4]
$$

Un valor positivo en la ecuación [4] indica que la tasa de acumulación del capital está aumentando; esto es que dGI > dISR, lo que quiere decir que dIIG > -dIRP; un valor negativo del diferencial indica que la tasa de acumulación (ino el stock!) del capital disminuye; es decir que dGI < dISR, esto quiere decir que $\square$ dIIG $<-$ dIRP.

En otras palabras, en tanto la tasa de "inequidad del gasto" sea mayor que el inverso aditivo de la "redistribución perversa", tanto mayor será la capacidad de acumulación del modelo, y esto se optimiza cuando la tasa de interés (la carga de intereses sobre los ingresos) aumenta. Dicho de otra forma, a los efectos perniciosos que la existencia de un crowding out supone, una elevación de las tasas de interés agrega al encarecimiento del costo del dinero en el tiempo, la limitación del acceso a los medios de producción tanto para las generaciones futuras (desde una perspectiva ricardiana), como los actuales propietarios del trabajo; todo ello como manifestación del efecto de una potenciación de la tasa de acumulación del capital.

Este proceso ha tenido épocas en las cuales se ha acentuado y que han coincidido, obviamente, con aquellos momentos del tiempo en el que los Gastos en Intereses han representado una magnitud importante. Los últimos años, desde el inicio del milenio, han sido unos en los cuales las transferencias a las personas han significado un destino feliz de la recaudación de los ingresos por concepto del Impuesto sobre Renta. No obstante, en concordancia con el deterioro en la equidad del gasto, la redistribución perversa vuelve a manifestarse como una tendencia desde inicios del año 2003 a la fecha.

Ahora bien, el mecanismo de transmisión de este proceso viene a ser lo que se ha denominado la "Tasa de Acumulación del Capital Financiero" ( $\tau)$, la cual, como se aprecia, sigue un comportamiento determinado por el interés pagado en promedio por la deuda bonificada del Gobierno 5 . 


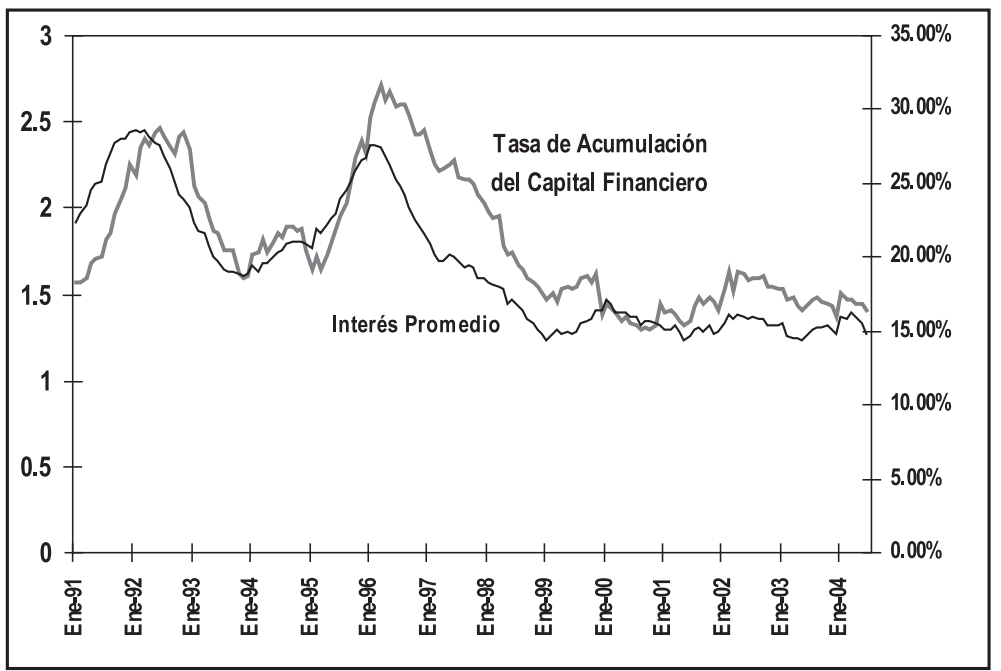

Ilustración 5. Costa Rica: Tasa de Acumulación del Capital Financiero e Interés Promedio de la Deuda Bonificada del Gobierno Enero 1991 - Junio 2004

Fuente: Elaboración propia, partiendo de cifras recopiladas por CEFSA

Lo anterior pone de manifiesto un hecho relevante: Elevaciones de la tasa de interés promedio (que harán elevar el pago de intereses) se traducirán como elevaciones de la Tasa de Acumulación del Capital Financiero, propiciando la redistribución perversa de las rentas al interior de la economía.

Con ello, los Gastos de Intereses sobre la deuda bonificada del Gobierno no sólo constituyen el vehículo de acumulación del capital financiero, sino que el rédito que tal deuda bonificada paga se transforma, a la postre, en la tasa a la cual se acumula dicho capital y en el mecanismo de extracción desde los generadores de renta hacia los poseedores de la riqueza financiera.

\section{Una digresión....}

Se podría analizar el impacto que tiene este tipo de mecanismo de acumulación del capital financiero en la derivación de la utilidad de los agentes económicos. Para ello se concebirá una función de utilidad que depende estrictamente del consumo de los agentes económicos y éste, a su vez, depende del nivel de ingreso disponible $(Y d)$ y de la tasa de interés $(i)$; positivamente del nivel de ingreso disponible y en forma inversa de la tasa de interés:

$$
U(C)=U(Y d, i)
$$

Ahora bien, el ingreso disponible puede describirse genéricamente de la siguiente forma: 


$$
Y d=y(\ldots)-I S R+\operatorname{Tr} N
$$

Es decir, el ingreso disponible $(Y d)$ será la suma de los ingresos corrientes $(y(\ldots))$ los cuales dependerán de la forma habitual de generar ingresos de los agentes, los Impuestos Directos (ISR: Impuestos sobre Renta) y las Transferencias Netas (TrN). De esta manera se podrían distinguir dos grandes grupos de agentes: aquellos que derivan su ingreso corriente de la aplicación del trabajo, y aquellos que lo derivan de los ingresos de su acervo de capital (hablaremos del capital financiero, en forma particular):

$$
\begin{aligned}
& Y d_{1}=y(\underset{+}{L, w)}-I S R+\operatorname{TrN} \\
& Y d_{2}=y(\underset{+}{K f}, i)-I S R+\operatorname{Tr} N
\end{aligned}
$$

Incorporando la información proveniente de la ecuación [3] en el esquema de la ecuación [6] y de ésta en la [5], se podría tener:

$$
U(Y d, i)=\underset{+}{U(I R P, I I G)}
$$

Lo cual es cierto para los participantes del grupo 1, que generan su renta corriente en virtud de la aplicación de su trabajo, pues un incremento en IRP se daría si aumentan las Transferencias Netas (TrN) o una reducción en el Impuesto sobre Renta (ISR), lo que aumentaría el ingreso disponible y, con ello, la utilidad de los agentes económicos. Por otra parte, un aumento del indicador IIG se daría como consecuencia de una reducción de las Transferencias Netas (TrN) o un aumento del Gasto de Intereses (GI), que representaría una mayor aplicación del capital financiero en forma de deuda bonificada del Gobierno (Kf) o de la tasa de interés pagada por dicha deuda (i); siendo que este aumento en la tasa de interés reduciría el consumo en una función de utilidad convencional.

Ahora, si bien las direcciones de los cambios son previsibles en el caso de los agentes del grupo 1 (trabajadores y empresarios), no es tan claro en el caso de los agentes que pertenecen al grupo 2 (dueños del capital financiero), pues en este último caso, un incremento de los Gastos por Intereses (GI), se traduce en un incremento de la renta disponible; pues para este grupo, lo planteado por la ecuación [7] establece que la renta corriente aumentará ante el incremento del Gasto de Intereses sobre la deuda bonificada del Gobierno, merced ya a una mayor aplicación de capital financiero en forma de tal deuda (Kf aumentando), o en forma de una mayor tasa de interés.

En este caso se tendría, entonces:

$$
U(Y d, i)=U(I R P, I I G)
$$

Aquí el efecto negativo de la tasa de interés en las decisiones de consumo es compensado por la mayor renta que representa el flujo de Gasto de Intereses del Gobierno, que se convierte 
en una renta adicional para los dueños del capital financiero, como se representa en la siguiente ilustración:

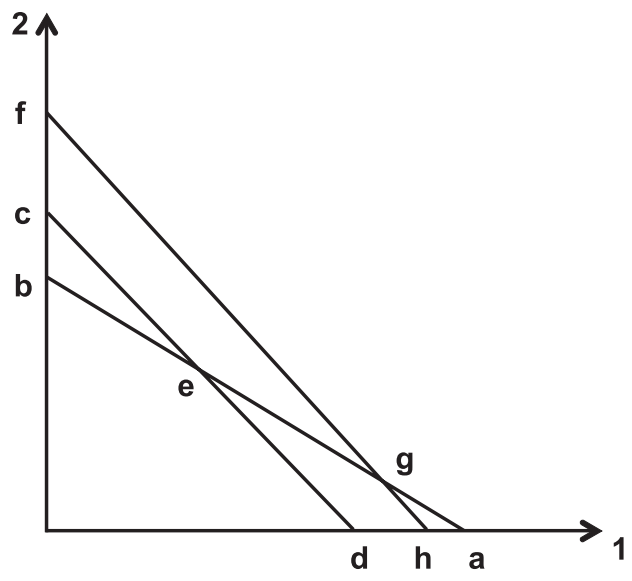

Ilustración 6. La restricción inicial está dada por la línea ab; al darse un aumento en la tasa de interés, la nueva restricción será cd, el cambio en utilidad dependerá de las preferencias temporales por el consumo. Esto es cierto para todos los agentes, independientemente de la forma en la que generan su renta. Para el caso del grupo que obtiene su renta por la aplicación del capital financiero (Kf), el aumento del ingreso disponible proveniente de la elevación de los tipos de interés, hace que su nueva restricción sea fh; habiendo una ganancia neta en términos de poder de compra, con respecto a la posición original de (fbg - hga).

Como se advierte, el Gasto en Intereses de parte del Gobierno se traduce en un mecanismo de transmisión de rentas desde aquellos agentes que derivan sus ingresos corrientes de la aplicación de la fuerza laboral, sobre quienes se imponen los gravámenes sobre renta (ISR), hacia a aquellos que derivan sus ingresos corrientes de la aplicación de su capital financiero en la forma de inversiones en bonos de deuda del gobierno; perjudicando las posibilidades de utilidad para los primeros y favoreciendo la de los segundos; en un claro proceso de redistribución perversa de la riqueza y de las posibilidades de consumo tanto contemporáneas como intertemporales.

\section{Conclusiones}

El estudio precedente permite dar una idea de las implicaciones que en el orden social tiene la forma en la que han venido creciendo los Gastos en Intereses de la Deuda Pública. Implicaciones que trascienden la mera composición del gasto público y que desmeritan el esfuerzo de parte del administrador de la Hacienda Pública por mantener un superávit primario, trocando tal situación en recurrentes déficit financieros, sino que van más allá.

Esto debido a que los cambios que sugiere el creciente comportamiento de los pagos por intereses, suponen la existencia de una reorganización en la estructura del gasto, el cual cada vez más se ha orientado a satisfacer el servicio de la deuda en detrimento de la acción 
del Estado en cuanto a la redistribución del ingreso; convirtiendo el pago de intereses en un mecanismo de redistribución perversa desde los que generan riqueza (por medio de las rentas) a quienes ya la poseen (los dueños del capital financiero).

Aquí la tasa de interés adquiere un nuevo halo: No es simplemente "el precio del dinero", el pago por renuncia al consumo actual, como lo verían los clásicos, es el mecanismo de extracción de la plusvalía a los generadores de renta, que se transforma en la tasa de acumulación del capital financiero para aquellos que poseen tal capital.

\section{Agradecimientos}

Quiero agradecer los comentarios de Matthias Arzbach.

\section{Notas}

1 En serie significa que gran cantidad de títulos dentro de cada grupo son iguales, que tienen las mismas características de tasas de interés, plazo y fecha de vencimiento, es decir, corresponden a un mismo patrón de pagos.

2 La razón ha sido calculada a partir de cifras anualizadas, denominando Gl: gasto de Intereses, SP: Superávit Primario; de la siguiente forma:

3 Obtenida mediante la fórmula

4 Ello permitió al país cumplir con sus compromisos y mejorar su calificación en los mercados internacionales, con el objetivo y propósito de colocar deuda en dichos mercados, en mejores condiciones que las ofrecidas por el mercado local, que pudiera financiar el proceso de privatización y venta de activos. Sin embargo, este proceso de privatización no se concretó por el inadecuado manejo de la escasa popularidad de tales medidas, pero sí se hizo uso del expediente de financiamiento que suponía la posibilidad que concediera la Ley de endeudamiento externo aprobada por la Asamblea Legislativa.

5 Este cálculo se ha efectuado como el promedio de 12 observaciones mensuales del cociente entre el monto pagado en intereses (Gasto de Intereses, GI) sobre el saldo de la deuda bonificada, lo que está relacionado con un concepto de "pago de interés" (tasa por tiempo) y no sólo con la tasa de interés.

\section{Referencias Bibliográficas}

-CONSEJEROS ECONÓMICOS Y FINANCIEROS, S.A. (CEFSA). Cifras sobre Finanzas Públicas. [Varios años]. San José, Costa Rica.

-MATARRITA, R. (1993a). Hacia la modificación de la estructura de la deuda bonificada del Fisco [en línea]. Documento RMV-1993-03. Disponible en Internet: www.capitales.com/ educacion.mhtml

-MATARRITA, R. (1993b). La deuda bonificada del Fisco: icómo cuesta volver al pasado! [en línea]. Documento RMV-1993-05. Disponible en Internet: www.capitales.com/educacion. mhtml

-MATARRITA, R. y LEDEZMA, J. (2004). Aspectos Generales del Mercado de Valores. Documento preparado para curso homónimo en FUNDEVAL. San José, Costa Rica: Bolsa Nacional de Valores, S.A.

-QUINTERO, N. y ROMERO, Y. (2004). Modificaciones en la Administración de la Deuda Pública: un análisis de los últimos 20 años. Trabajo de investigación en la Cátedra de Análisis de Instrumentos Financieros. Programa de Maestría en Economía. San José, Costa Rica: Universidad de Costa Rica. Mimeo. 